\title{
Coloration of Calcium Alginate Fiber with Base Dye
}

\author{
Ying-Jie GUO ${ }^{1, a}$, Yang-Shan LI ${ }^{1, b}$, Zhong-Jun FU ${ }^{1, c, *}$, Hao-Fei HUANG ${ }^{1, d}$ \\ ${ }^{1}$ School of Chemical Engineering, Shandong University of Technology, Zibo 255049, China \\ a627347276@qq.com, b47485431@qq.com, cyls9693@163.com, d1982hhf@163.com
}

Key words: Alginate Fiber, Base dye, Dyeing Property, Fastness

\begin{abstract}
In this work, a base dye was applied to the dyeing of calcium alginate fiber. The dyeing properties, including dyeing time, $\mathrm{pH}$ and temperature, were studied. The results showed that this dye had good affinity to alginate fiber, and the dyeing fastness was also good. This research may provide a new approach for the dyeing of calcium alginate fiber in the future.
\end{abstract}

\section{Introduction}

Alginate fiber is a kind of natural biological macromolecule material derived from seaweed. In fact the alginate fiber that we generally refers to is the calcium salt of alginic acid, namely calcium alginate fibers. It has a series of excellent properties, such as good moisture absorption, mechanical property, antioxidation, biodegradable and potential biocompatibility [1]. Besides, this fiber also has excellent performance in flame retardant [2], anti- electromagnetic radiation [3] and hygroscopic[4], compared with other natural textile material. Thus, it has a wide range application in functional textiles, especially in the field of medical textiles [5].

However, the application of this fiber in the textile field is restricted due to its poor dyeing properties with traditional dyeing process. This is mainly because of the gelation of alginate fiber in solutions containing sodium salt which is common additives in traditional dyeing methods. Till now, there are only several dye structures have been selected for the coloration of this fiber. In our work, a cationic base dye, Base red 5GN (structure shown in Figure 1), was applied to dye calcium alginate fiber. And the effect of different dyeing conditions were studied and discussed. The dyeing fastness and the physical property was also examined.

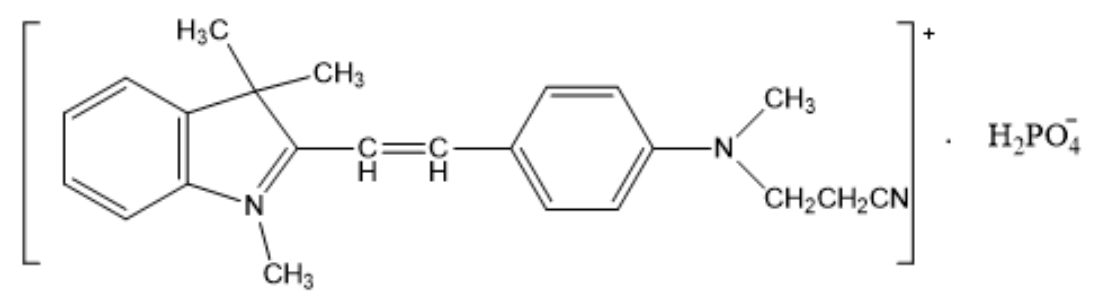

Fig.1 Structure of Base Red 5GN

\section{Materials and Equipment}

\section{Experimental Materials}

Calcium alginate fiber was purchased from Huafang Textile, Co. Ltd., China. Base Red 5GN was obtained from Shunlong Chemical Company, China. Other chemicals were all analytical grade and purchased from Bodi Chemcal Company, China.

\section{Laboratory Equipment}

The temperature was kept in HH-S therm ostat water bath (Zhengzhou Great Wall industry \&trade co., LTD). The $\mathrm{pH}$ value was controlled by PHS-3C precision acidity meter (Shanghai Anting Ray Magnetic Instrument Plant). K/S values were tested by X-rite 8400 color matching instrument (The United States X-rite). 


\section{Dyeing Process}

The dyeing was carried out in a bath containing $2 \%$ o.w.f dye (based on the fabric mass) at certain $\mathrm{pH}$ value (adjusted by $0.5 \mathrm{M} \mathrm{HCl}$ ) with a liquor ratio 30:1. Fiber was immerged into this dye bath at room temperature. Then it was heated to a given temperature and dyeing for a certain time. At last, the dyed fiber was removed from the dye-bath, rinsed and soaped-off using $1 \mathrm{~g} / \mathrm{L} \mathrm{OP}-10$ at boiling temperature for $10 \mathrm{~min}$. The dye-bath and soap-bath was then mixed and used to determine the final exhaustion\% rate.

\section{Color Fastness Test}

The color fastness of the dyed fabric was tested according to ISO-105-C06 international norms and in accordance with the AATCC 8-2001 test.

\section{Strength Property Test}

The breaking strength of calcium alginate fibers was measured with the electronic single fiber tensile strength tester (YG004E, NBFY company, China) and each sample was tested for 50 times with $20 \mathrm{~mm}$ space, $0.3 \mathrm{cN}$ pretension, and a $10 \mathrm{~mm} / \mathrm{min}$ stretching speed.

\section{Results and Discussion}

\section{Effect of Dyeing pH on K/S Value}

Figure 2 showed the effect of dyeing $\mathrm{pH}$ on the K/S value under conditions of $60{ }^{\circ} \mathrm{C}$ for $40 \mathrm{~min}$. The results showed that the $\mathrm{K} / \mathrm{S}$ value increased with $\mathrm{pH}$ value increasing. As is known, calcium alginate fiber contains much $-\mathrm{OH}$ and $-\mathrm{COOH}$ groups in its structure, which results in that the fiber is negative charge. The higher the $\mathrm{pH}$ value is, the higher electronegativity of alginate fiber. On the other hand, Base Red 5GN is cationic due to the quternary ammonium ions in its structure. Thus, the dye structure and fiber can be attracted by the strong ion-ion interaction. And, this force increased with $\mathrm{pH}$ increasing.

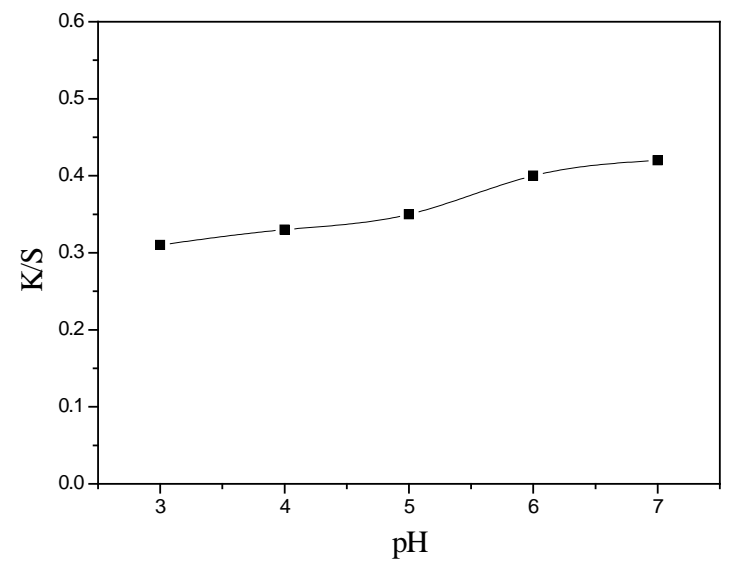

Fig. 2 Effect of dyeing $\mathrm{pH}$ on K/S value

\section{Effect of Dyeing Temperature on K/S Value}

To investigate the effect of dyeing temprature on K/S of dyed fiber, dyeings were carried out at conditions of $\mathrm{pH} 6$ for 40 min. The results were summerized in Figure 3. It was clear that the high temperature showed positive effect on K/S. Due to the compact structure of calcium alginate fiber which is generally described as an "egg-box" structure, it is difficult for dye molecule to penetrate the fiber. Thus, with temperature increasing, the fiber will be swelling and make the migration of dye molecule much easier. So, a high dyeing temperature was recommended. 


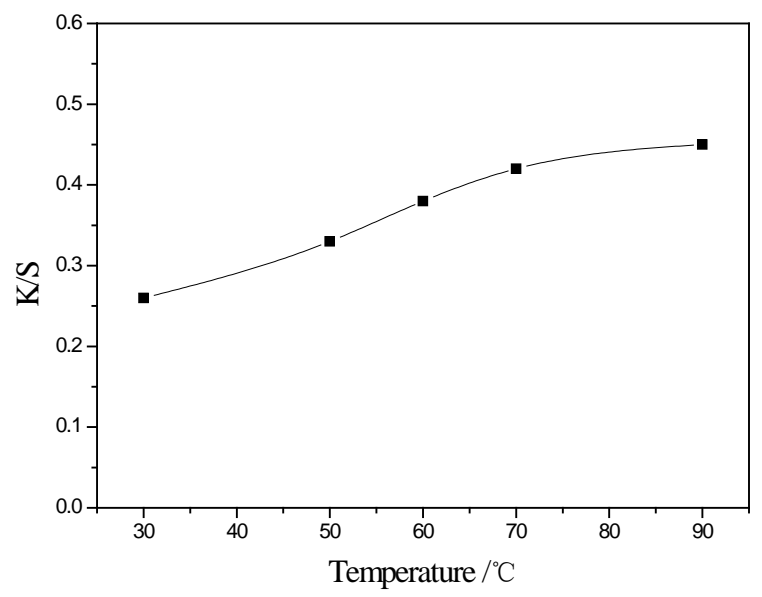

Fig. 3 Effect of dyeing temperature on K/S value

\section{Effect of Dyeing Time on K/S Value}

Dyeing time is another important dyeing parameters affecting the dyeing performance, so the effect of dyeing time on the dyeing property of Base Red 5GN was also studied and the results were shown in Figure 4. It can be seen that the adsorption rate of this dye was very fast and the dye reached saturation after only $20 \mathrm{~min}$. This was also attributed to the strong coulombian force between fiber and base dye.

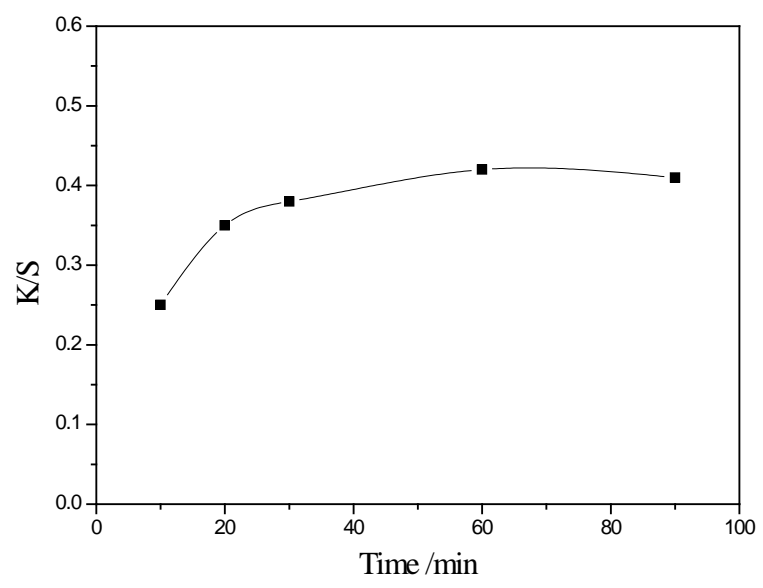

Fig. 4 Effect of dyeing time on K/S value

\section{Dyeing Fastness and Physical Properties of Dyed Fiber}

The rub-fastness and washing fastness were tested, and they were all 3-4 grade. And, after dyeing, the strength loss of this fiber was tested, and only slightly loss of $7 \%$ was observed. This was because that no salt addition in the dyeing process and the dyeing conditions were quite mild.

\section{Conclusion}

In this paper, a cationic base dye was selected and applied to the dyeing of calcium alginate fiber. The affinity between fiber and dye is mainly due to the strong coulombian force derived from negative charged fiber and cationic dye. The optimal dyeing conditions of experiment were as follows: dyeing at $\mathrm{pH} 7$ and $90{ }^{\circ} \mathrm{C}$ for $60 \mathrm{~min}$. Under the optimum conditions, the optimal $\mathrm{K} / \mathrm{S}$ value reached 0.45 . 


\section{Reference}

[1] Bajpai, S., \& Sharma, S. (2004). Investigation of swelling/degradation behaviour of alginate beads crosslinked with Ca 2+ and Ba 2+ ions. Reactive and Functional Polymers, 59(2), 129-140.

[2] Fan, L., Du, Y., Zhang, B., Yang, J., Zhou, J., \& Kennedy, J. F. (2006). Preparation and properties of alginate/carboxymethyl chitosan blend fibers. Carbohydrate Polymers, 65(4), 447-452.

[3] Kumar, R. S. (2013). Textiles for industrial applications. CRC Press.

[4] Li, Y., Zhang, S., Yang, J., Jiang, S., \& Li, Q. (2008). Synthesis and application of novel crosslinking polyamine dyes with good dyeing performance. Dyes and Pigments, 76(2), 508-514.

[5] Lv, F., Zhu, P., Wang, C., \& Zheng, L. (2012). Preparation, characterization, and dyeing properties of calcium alginate fibers. Journal of Applied Polymer Science, 126(S1), E383-E388.

[6] Qin, Y. (2008a). Alginate fibres: an overview of the production processes and applications in wound management. Polymer international, 57(2), 171-180.

[7] Qin, Y. (2008b). The gel swelling properties of alginate fibers and their applications in wound management. Polymers for Advanced Technologies, 19(1), 6-14. 